\title{
Symptoms of psychiatric diseases in a pediatric neurology department
}

Izabela Kaczmarek ${ }^{1}$, Ewelina Kucharska², Katarzyna Cioczek², Barbara Steinborn³

\author{
${ }^{1}$ Laboratory of Developmental Neuropsychology, Department and Clinic \\ of Developmental Neurology, Poznan University of Medical Science, Poznan, Poland \\ 2Department of Developmental Neuropsychology, Heliodor Swiecicki Clinical Hospital, \\ Poznan, Poland \\ ${ }^{3}$ Department and Clinic of Developmental Neurology, Poznan University of Medical \\ Science, Poznan, Poland
}

Submitted: 6 March 2017

Accepted: 26 March 2017

Arch Med Sci Civil Dis 2017; 2: e78-e84

DOI: https://doi.org/10.5114/amscd.2017.67109

Copyright (c) 2017 Termedia \& Banach

\section{Abstract}

Introduction: The present study investigated the comorbidity of psychiatric symptoms among patients with neurological diseases and the possibility of the symptoms of mental disorders being masking by the symptoms of somatic disorders.

Material and methods: Eight thousand two hundred and one epicrises of all patients hospitalized at the Department of Developmental Neurology from $1^{\text {st }}$ January 2003 to $31^{\text {st }}$ December 2013 were analyzed in order to select a group of patients referred for consultation with a child psychiatrist. The epicrises were analyzed in terms of diagnosis and the most common psychopathological symptoms on the basis of the State-Trait Anxiety Inventory, State-Trait Anxiety Inventory for Children, Eysenck Personality Questionnaire-Revised, Beck Depression Inventory, and the Schedule for Affective Disorders and Schizophrenia for School-Aged Children - Present and Lifetime (K-SADS-PL).

Results: As a result of the analysis a group of 345 patients with serious symptoms requiring psychiatric consultation was selected. In the selected group, patients had the diagnosis of neurological as well as psychiatric diseases. The most frequently mentioned were: epilepsy (13.3\%), emotional disorders (11.3\%), tension-type headaches (11.3\%) and conversion disorders (8.4\%). Dominating psychopathological symptoms were: anxiety (64\%), symptoms of mood disorders (31.6\%) and signs of inattention (19.7\%). Suicidal ideation was manifested by $21(6.08 \%)$ persons.

Conclusions: There is a need for careful observation of the mental state of each patient of a pediatric neurology department by an interdisciplinary team of doctors, psychologists and support staff.

Key words: neurological diseases, psychiatric consultations, comorbidities.

\section{Introduction}

The diagnosis of mental disorders in children and adolescents with disorders of the nervous system is an important issue in diagnosing and treating co-occurring symptoms in pediatric neurology. It is an interesting subject from the point of view of the knowledge of the symptomatology of neurological disorders and "borderline" psychiatric symptoms, linking these two areas into the so-called neuropsychiatric syndromes.

\author{
Corresponding author: \\ Dr. Izabela Kaczmarek \\ Laboratory of \\ Developmental \\ Neuropsychology \\ Department and Clinic \\ of Developmental \\ Neurology \\ Poznan University \\ of Medical Science \\ 49 Przybyszewskiego St \\ 60-355 Poznan, Poland \\ Phone: +48 618691729 \\ E-mail: ikaczmarek@ump. \\ edu.pl
}


The most important aspect of the diagnosis of mental disorders is, however, the possibility to design appropriate interventions to protect the patient from serious long-term consequences of remaining without the proper medical care - in this case without psychiatric care. The relationship between mental disorders and somatic diseases has been widely studied for years now. Due to the etiology of psychopathological symptoms, it has been assumed that they can occur in, at least, four variants. In the first variant, a somatic disease underlies mental disorders, and the manifested psychopathological symptoms are treated as secondary to the underlying somatic condition (e.g. in the course of endocrine and metabolic diseases) [1]. The second option takes place when psychiatric symptoms are initially manifested "in the form of" somatic disorders [2, 3], mostly as pain or vegetative symptoms (e.g. sleep or appetite disorders) [4, 5]. This type of somatic symptoms often gives a pretext to search for the medical causes of problems among physicians of various specialties associated with the symptoms. The patient himself is then subjected to numerous diagnostic tests which, in the end, do not bring answers to the question about the cause of the reported ailments. The third option refers to the co-occurrence of psychological symptoms and a disease of the nervous system [6], as it happens, for example, in the case of patients with epilepsy [7], and the so-called "dual diagnosis" [6]. Finally, under the fourth variant, psychiatric symptoms are induced by the use of psychoactive substances or by a pharmacological treatment [8].

According to the estimates of the World Health Organization, mental disorders affect about 10$20 \%$ of children and adolescents, and it seems that this percentage is constantly growing [9]. However, the problem of the occurrence or mutual dependencies of mental disorders in somatic diseases in children and adolescents still remains an insufficiently explored issue. Much research has been devoted to the problem of the comorbidity of psychiatric disorders in other psychiatric disorders, for example, to the occurrence of mood disorders or psychoactive substance abuse in attention-deficit/hyperactivity disorder [10], mood disorders in post-traumatic stress syndrome [11], or symptoms coexisting in mood disorders or obsessive-compulsive disorder [12]. Relatively little research has been devoted to the group of child and adolescent patients with diseases of the nervous system, in whom there simultaneously appear signs of a spectrum of mental disorders that require treatment. The comorbidity of neurological and psychiatric disorders has been described, among others, in children with headaches [13, 14], migraine [15], tic disorder [16], Tourette's syndrome [17], juvenile multiple sclerosis [18] and epilepsy [7, 19]. The present work discusses the characteristics of patients from a diagnostic developmental neurology department, who manifested severe signs of mental problems and, as a result, were in need of a psychiatric consultation. The authors attempted to determine which group of patients required a consultation, and which accompanying psychopathological symptoms were the most frequent.

\section{Material and methods}

The presented results are based on a retrospective analysis of medical records of patients diagnosed in the Department of Developmental Neurology between January $1^{\text {st }}, 2003$ and December $31^{\text {st }}, 2013$, and referred for a consultation to a child psychiatrist by the attending physician. In order to identify this group of patients, initially 8201 epicrises of all patients hospitalized during this period of time were analyzed. The criterion for the inclusion of the patient's documentation for further analysis was the information about the attending physician's request for a psychiatric consultation. As a result, 345 patients' histories were selected. Then, the selected medical histories were analyzed with respect to the formulated diagnosis (main diagnosis and comorbidity) and the frequency of the most common psychopathological symptoms described in the epicrisis and/ or in the psychological examination, and assigned to the following categories: i) symptoms of mood disorders, ii) symptoms of psychotic disorders, iii) symptoms of behavioral disorders, including aggression and severe hyperactivity, iv) signs of somatoform disorders, v) anxiety and vi) problems in social relations. The analysis also revealed patients with suicidal ideation. The assignment of patients to particular groups was possible thanks to the information included in their medical history and the results of the conducted psychological tests, including: the State-Trait Anxiety Inventory, the State-Trait Anxiety Inventory for Children, the Eysenck Personality Questionnaire - Revised, the Beck Depression Scale, the Standardized questionnaire interview tool for oppositional-defiant and behavioral disorders according to DSM-IV-TR, the Standardized questionnaire interview tool for attention deficit hyperactivity disorder according to ICD-10 and DSM-IV-TR, and the Schedule for Affective Disorders and Schizophrenia for School-Aged Children - Present and Lifetime (K-SADS-PL). The classification of patients into groups of different disorders was carried out by two independent competent judges.

\section{Statistical analysis}

The conducted analyses included descriptive statistics and an analysis of the diversity of di- 
agnoses carried out in the procedure of multiple responses. This analysis allows one to determine which diagnosis was the most/least common. The descriptive analyses were conducted using SPSS version 12.0 (SPSS Inc., Chicago, USA).

\section{Results}

The identified group of patients with the decision to consult a psychiatrist consisted of 345 individuals, which represented $4.3 \%$ of all patients diagnosed in the department during the investigated period of time. The age ranged from 9.0 to 16.9 years $(M=12.96, S D=3.96)$.

\section{Main diagnoses and comorbidities}

The analysis of the diagnoses showed that $63.19 \%$ (218) of the patients were diagnosed with one disease and $36.81 \%$ (127) had more than one diagnosis. Eventually, $60.87 \%(n=210)$ of the patients had as their first diagnosis a condition from the category of mental illnesses, dominated by emotional and somatoform disorders. Taking into account the main diagnoses in the analyzed group, the largest group constituted the patients with epilepsy ( $n=46 ; 13.3 \%)$, followed by the patients with: emotional disorders ( $n=39 ; 11.3 \%)$, tension-type headaches ( $n=39 ; 11.3 \%)$, conversion disorder ( $n=29 ; 8.4 \%)$, and attention deficits with hyperactivity $(n=24 ; 7.0 \%)$. A summary of the results is presented in Table I. The table in cludes the main diagnoses and comorbidities (the first comorbid diagnosis (1) and the second comorbid diagnosis (2)).

The type of psychopathological symptoms among 345 patients requiring a psychiatric consultation

In the group of patients diagnosed with a disease of the nervous system as the main diagnosis, anxiety was the most common psychopathological symptom. In order of occurrence, it could be observed in the patients with syncope ( $n=26 ; 86.7 \%)$, tension headaches ( $n=35 ; 71.4 \%)$, epilepsy $(n=33$; $63.5 \%)$ and migraine $(n=7 ; 63.6 \%)$. Psychotic symptoms occurred most often in the patients with epilepsy ( $n=7 ; 13.5 \%)$, syncope $(n=3 ; 10 \%)$ and tension-type headaches ( $n=2 ; 4.1 \%)$. Hyperactivity was observed most frequently in the patients with tension headache $(n=3 ; 6.1 \%)$ and in the patients with epilepsy ( $n=3 ; 5.8 \%)$. Signs of mood disorders were reported in the patients with migraine $(n=7$; $63.6 \%$ ), tension headaches ( $n=22 ; 44.9 \%$ ), syncope $(n=12 ; 40 \%)$, and epilepsy $(n=12 ; 23.1 \%)$. Attention deficits were most frequent in the patients with epilepsy ( $n=14 ; 26.9 \%)$ and syncope $(n=5$; $16.7 \%$ ). Signs of somatoform disorders were most often found in the patients with tension headaches $(n=5 ; 10.2 \%)$ and epilepsy $(n=3 ; 5.8 \%)$. Aggression occurred in $9(17.3 \%)$ patients with epilepsy and in $5(10.2 \%)$ patients with tension-type headaches. Serious problems in the regulation of social behavior were observed in $6(11.5 \%)$ patients with epilepsy. Table II presents a summary of the observed psychopathological disorders, taking into account both the neurological and the psychiatric diagnoses.

\section{Suicidal ideation}

Suicidal ideations occurred in 21 patients: 5 patients with mood disorders, 5 patients with tension-type headaches, 3 patients with epilepsy, 3 patients with conversion disorder, 2 patients with emotional disorders, 1 patient with migraine, 1 patient with hyperkinetic disorder and 1 patient with syncope.

\section{Discussion}

Despite the relatively large number of studies describing prodromes in psychiatric disorders, for example, in bipolar disorder [20] or depression [21], there are limited data in the available literature about the percentage of children and adolescents with somatic symptoms equivalent to the symptoms indicative of a mental illness. Some light on the somatic and psychological condition of schoolchildren was thrown by a survey of health behavior conducted among 200000 adolescents in 43 countries in Europe and North America [22]. The report pertains, among others, to subjective psychosomatic disorders, including abdominal pain, headaches, back pain, dizziness and difficulty falling asleep. Signs of depression, irritability and anxiety were also assessed. Among the Polish respondents, as many as one in five reported the occurrence of a chronic disease and accompanying stress [23]. Somatic symptoms may be an expression of prolonged exposure to stress, which in children and adolescents may be associated with multiple causes, for example, lack of acceptance, school stress, insufficient support in the immediate family, or bullying. However, there still remains the question about the percentage of respondents who would require specialist care and the percentage of somatic symptoms that might mask or predict mental disorders in the future. The work of Shanahan et al. [24] shows a clear link between somatic complaints in childhood and emotional disorders later in life. The authors claim that "Four hundred and sixty-four children (34.4\%; all percentages weighted) in the analytic sample reported somatic complaints during at least one assessment between ages 9-16 years. [...] headaches were the most common somatic complaints (24.7\%), followed by stomach aches (9.6\%), and 
Table I. Frequency of particular diagnoses depending on their order of occurrence

\begin{tabular}{|c|c|c|c|c|c|c|}
\hline \multirow[t]{2}{*}{ Parameter } & \multicolumn{2}{|c|}{ Main diagnosis ${ }^{1}$} & \multicolumn{2}{|c|}{ Comorbidity $1^{2}$} & \multicolumn{2}{|c|}{ Comorbidity $2^{3}$} \\
\hline & $N$ & $\%$ & $N$ & $\%$ & $N$ & $\%$ \\
\hline \multicolumn{7}{|l|}{ Neurological disorders: } \\
\hline Epilepsy & 46 & 13.3 & 6 & 4.7 & 0 & 0 \\
\hline Tension-type headache & 39 & 11.3 & 9 & 7.0 & 1 & 4.2 \\
\hline Syncope & 19 & 5.5 & 9 & 7.0 & 2 & 8.3 \\
\hline Migraine & 10 & 2.9 & 1 & 0.8 & 0 & 0 \\
\hline Sleep disorder & 5 & 1.4 & 4 & 3.1 & 0 & 0 \\
\hline Arachnoid cyst & 2 & 0.6 & 3 & 2.3 & 1 & 4.2 \\
\hline Dizziness & 2 & 0.6 & 1 & 0.8 & 0 & 0 \\
\hline Bedwetting & 1 & 0.3 & 2 & 1.6 & 1 & 4.2 \\
\hline Extrapyramidal disorders & 1 & 0.3 & 0 & 0 & 0 & 0 \\
\hline Head trauma & 1 & 0.3 & 0 & 0 & 0 & 0 \\
\hline Cerebellar syndrome & 1 & 0.3 & 0 & 0 & 0 & 0 \\
\hline Polyneuropathy & 1 & 0.3 & 0 & 0 & 0 & 0 \\
\hline Myopathy & 1 & 0.3 & 0 & 0 & 0 & 0 \\
\hline Essential tremor & 0 & 0 & 1 & 0.8 & 0 & 0 \\
\hline Pineal cyst & 0 & 0 & 2 & 1.6 & 1 & 4.2 \\
\hline Congenital corpus callosum & 0 & 0 & 1 & 0.8 & 0 & 0 \\
\hline Cerebral palsy & 0 & 0 & 1 & 0.8 & 0 & 0 \\
\hline \multicolumn{7}{|l|}{ Mental disorders: } \\
\hline Conversion disorders & 39 & 11.3 & 14 & 10.9 & 4 & 16.7 \\
\hline Emotional disorders & 29 & 8.4 & 11 & 8.6 & 0 & 0 \\
\hline Hyperkinetic disorder & 24 & 7.0 & 3 & 2.3 & 0 & 0 \\
\hline Mood disorders & 17 & 4.9 & 18 & 14.1 & 1 & 4.2 \\
\hline Mental retardation & 17 & 4.9 & 6 & 4.7 & 2 & 8.3 \\
\hline Pervasive developmental disorders & 17 & 4.9 & 4 & 3.1 & 0 & 0 \\
\hline Mixed disorders of conduct and emotions & 16 & 4.6 & 7 & 5.5 & 0 & 0 \\
\hline Tic disorder & 15 & 4.3 & 1 & 0.8 & 2 & 8.3 \\
\hline Conduct disorder & 9 & 2.6 & 6 & 4.7 & 1 & 4.2 \\
\hline Psychotic disorders & 9 & 2.6 & 2 & 1.6 & 0 & 0 \\
\hline $\begin{array}{l}\text { Specific developmental disorders of speech and } \\
\text { language }\end{array}$ & 5 & 1.4 & 2 & 1.6 & 0 & 0 \\
\hline Anxiety disorders & 4 & 1.2 & 2 & 1.6 & 1 & 4.2 \\
\hline Obsessive-compulsive disorder & 4 & 1.2 & 2 & 1.6 & 0 & 0 \\
\hline Eating disorders & 2 & 0.6 & 1 & 0.8 & 0 & 0 \\
\hline Tourette's syndrome & 2 & 0.6 & 0 & 0 & 0 & 0 \\
\hline Specific developmental disorders of scholastic skills & 1 & 0.3 & 3 & 2.3 & 2 & 8.3 \\
\hline Post-traumatic stress disorder & 1 & 0.3 & 0 & 0 & 1 & 4.2 \\
\hline \multicolumn{7}{|l|}{ Other: } \\
\hline Streptococcal allergization & 2 & 0.6 & 2 & 1.6 & 0 & 0 \\
\hline Diabetes & 2 & 0.6 & 1 & 0.8 & 0 & 0 \\
\hline Toxoplasmosis & 1 & 0.3 & 1 & 0.8 & 1 & 4.2 \\
\hline Short stature & 0 & 0 & 2 & 1.6 & 0 & 0 \\
\hline Systemic lupus erythematosus & 0 & 0 & 0 & 0 & 1 & 4.2 \\
\hline Astigmatism & 0 & 0 & 0 & 0 & 2 & 8.3 \\
\hline Total & 345 & 100.0 & 128 & 100.0 & 24 & 100.0 \\
\hline
\end{tabular}

${ }^{1}$ main diagnosis, ${ }^{2}$ comorbidity 1 - additional diagnosis given as the first after the main one, ${ }^{3}$ comorbidity 2 - additional diagnosis given as the next one. 
Table II. Frequency of psychopathological symptoms in particular diagnoses

\begin{tabular}{|c|c|c|c|c|c|c|c|c|c|c|}
\hline \multirow[t]{2}{*}{ Diagnosis } & \multicolumn{9}{|c|}{ Psychopathological symptoms (total) } & \multirow[t]{2}{*}{ Total } \\
\hline & Anxiety & $\begin{array}{l}\text { Psy- } \\
\text { chotic } \\
\text { symp- } \\
\text { toms }\end{array}$ & $\begin{array}{l}\text { Hyper- } \\
\text { activity }\end{array}$ & $\begin{array}{l}\text { Obses- } \\
\text { sive } \\
- \text { com- } \\
\text { pulsive } \\
\text { symp- } \\
\text { tomes }\end{array}$ & $\begin{array}{l}\text { Symp- } \\
\text { toms of } \\
\text { mood } \\
\text { disor- } \\
\text { der }\end{array}$ & $\begin{array}{l}\text { Aggres- } \\
\text { sion }\end{array}$ & $\begin{array}{l}\text { Inatten- } \\
\text { tion }\end{array}$ & $\begin{array}{l}\text { Prob- } \\
\text { lems in } \\
\text { social } \\
\text { rela- } \\
\text { tions }\end{array}$ & $\begin{array}{c}\text { Soma- } \\
\text { toform } \\
\text { symp- } \\
\text { toms }\end{array}$ & \\
\hline \multirow{2}{*}{$\begin{array}{l}\text { Emotional } \\
\text { disorders }\end{array}$} & 41 & 3 & 2 & 2 & 27 & 2 & 11 & 6 & 6 & \multirow[t]{2}{*}{57} \\
\hline & $71.9 \%$ & $5.3 \%$ & $3.5 \%$ & 3.5 & $47.4 \%$ & $3.5 \%$ & $19.3 \%$ & $10.5 \%$ & $10.5 \%$ & \\
\hline \multirow{2}{*}{$\begin{array}{l}\text { Tension-type } \\
\text { headache }\end{array}$} & 35 & 2 & 3 & 1 & 22 & 5 & 2 & 1 & 5 & \multirow[t]{2}{*}{49} \\
\hline & $71.4 \%$ & $4.1 \%$ & $6.1 \%$ & $2.0 \%$ & $44.9 \%$ & $10.2 \%$ & $4.1 \%$ & $2.0 \%$ & $10.2 \%$ & \\
\hline \multirow[t]{2}{*}{ Epilepsy } & 33 & 7 & 3 & 1 & 12 & 9 & 14 & 6 & 3 & \multirow[t]{2}{*}{52} \\
\hline & $63.5 \%$ & $13.5 \%$ & $5.8 \%$ & $1.9 \%$ & $23.1 \%$ & $17.3 \%$ & $26.9 \%$ & $11.5 \%$ & $5.8 \%$ & \\
\hline \multirow{2}{*}{$\begin{array}{l}\text { Conversion } \\
\text { disorders }\end{array}$} & 35 & 1 & 0 & 0 & 10 & 3 & 5 & 0 & 11 & \multirow[t]{2}{*}{40} \\
\hline & $87.5 \%$ & $2.5 \%$ & $0.0 \%$ & $0.0 \%$ & $25.0 \%$ & $7.5 \%$ & $12.5 \%$ & $0.0 \%$ & $27.5 \%$ & \\
\hline \multirow[t]{2}{*}{ Syncope } & 26 & 3 & 0 & 0 & 12 & 2 & 5 & 1 & 2 & \multirow[t]{2}{*}{30} \\
\hline & $86.7 \%$ & $10.0 \%$ & $0.0 \%$ & $0.0 \%$ & $40.0 \%$ & $6.7 \%$ & $16.7 \%$ & $3.3 \%$ & $6.7 \%$ & \\
\hline \multirow{2}{*}{$\begin{array}{l}\text { Mood } \\
\text { disorders }\end{array}$} & 33 & 5 & 1 & 0 & 20 & 1 & 8 & 5 & 1 & \multirow[t]{2}{*}{36} \\
\hline & $91.7 \%$ & $13.9 \%$ & $2.8 \%$ & $0.0 \%$ & $55.6 \%$ & $2.8 \%$ & $22.2 \%$ & $13.9 \%$ & $2.8 \%$ & \\
\hline \multirow{2}{*}{$\begin{array}{l}\text { Mental } \\
\text { retardation }\end{array}$} & 9 & 1 & 4 & 1 & 4 & 5 & 7 & 3 & 0 & \multirow[t]{2}{*}{25} \\
\hline & $36.0 \%$ & $4.0 \%$ & $16.0 \%$ & $4.0 \%$ & $16.0 \%$ & $20.0 \%$ & $28.0 \%$ & $12.0 \%$ & $0.0 \%$ & \\
\hline \multirow{2}{*}{$\begin{array}{l}\text { Mixed } \\
\text { behavioral } \\
\text { and } \\
\text { emotional } \\
\text { disorder }\end{array}$} & 16 & 3 & 5 & 0 & 6 & 5 & 3 & 2 & 0 & \multirow[t]{2}{*}{23} \\
\hline & $69.6 \%$ & $13.0 \%$ & $21.7 \%$ & $0.0 \%$ & $26.1 \%$ & $21.7 \%$ & $13.0 \%$ & $8.7 \%$ & $0.0 \%$ & \\
\hline \multirow{2}{*}{$\begin{array}{l}\text { Psychotic } \\
\text { disorders }\end{array}$} & 5 & 8 & 0 & 0 & 4 & 1 & 2 & 3 & 0 & \multirow[t]{2}{*}{11} \\
\hline & $45.5 \%$ & $72.7 \%$ & $0.0 \%$ & $0.0 \%$ & $36.4 \%$ & $9.1 \%$ & $18.2 \%$ & $27.3 \%$ & $0.0 \%$ & \\
\hline \multirow[t]{2}{*}{ Migraine } & 7 & 0 & 0 & 0 & 7 & 1 & 1 & 2 & 1 & \multirow[t]{2}{*}{11} \\
\hline & $63.6 \%$ & $0.0 \%$ & $0.0 \%$ & $0.0 \%$ & $63.6 \%$ & $9.1 \%$ & $9.1 \%$ & $18.2 \%$ & $9.1 \%$ & \\
\hline \multirow{2}{*}{$\begin{array}{l}\text { Hyperkinetic } \\
\text { disorder }\end{array}$} & 3 & 1 & 18 & 0 & 3 & 9 & 14 & 0 & 0 & \multirow[t]{2}{*}{27} \\
\hline & $11.1 \%$ & $3.7 \%$ & $66.7 \%$ & $0.0 \%$ & $11.1 \%$ & $33.3 \%$ & $51.9 \%$ & $0.0 \%$ & $0.0 \%$ & \\
\hline \multirow[t]{2}{*}{ Tics } & 14 & 3 & 0 & 1 & 2 & 2 & 7 & 1 & 0 & \multirow[t]{2}{*}{18} \\
\hline & $77.8 \%$ & $16.7 \%$ & $0.0 \%$ & $5.6 \%$ & $11.1 \%$ & $11.1 \%$ & $38.9 \%$ & $5.6 \%$ & $0.0 \%$ & \\
\hline \multirow{2}{*}{$\begin{array}{l}\text { Pervasive } \\
\text { development } \\
\text { disorders }\end{array}$} & 6 & 0 & 2 & 0 & 0 & 2 & 4 & 19 & 0 & \multirow[t]{2}{*}{21} \\
\hline & $28.6 \%$ & $0.0 \%$ & $9.5 \%$ & $0.0 \%$ & $0.0 \%$ & $9.5 \%$ & $19.0 \%$ & $90.5 \%$ & $0.0 \%$ & \\
\hline Conduct & 5 & 2 & 2 & 0 & 6 & 10 & 2 & 0 & 0 & 16 \\
\hline & $31.3 \%$ & $12.5 \%$ & $12.5 \%$ & $0.0 \%$ & $37.5 \%$ & $62.5 \%$ & $12.5 \%$ & $0.0 \%$ & $0.0 \%$ & \\
\hline
\end{tabular}

muscle aches (8.4\%)". In their opinion, "the presence of somatic complaints in childhood is an early marker that is much easier to detect and carries less stigma compared to other markers of risk for later emotional distress including parental psy- chopathology, previous psychiatric disorder, and maltreatment." (ibid. p. 1727).

In the described group of patients diagnosed with a neurological condition as the main disease, symptoms of mental disorders that required spe- 
cialized interventions were observed in the children with epilepsy, tension-type headaches, syncope, migraine, polyneuropathy and myopathy. Research by Davies et al. shows that mental disorders are present in $9.3 \%$ of the healthy population of children and adolescents, in $10.6 \%$ of patients treated for chronic diseases (e.g. diabetes), in $26 \%$ of children treated neurologically for epilepsy, and in as many as $56 \%$ of patients with complications in the course of epilepsy [25]. The group of patients with epilepsy is also exposed to a greater risk of suicide than the general population [26]. In the group of patients with epilepsy investigated by us, suicidal ideation occurred in 3 persons, and these patients frequently manifested symptoms of anxiety, affective disorders, attention disorders and psychotic disorders. The second largest group with a neurological disease and significant symptoms of mental disorders were the children and adolescents with headaches, frequent symptoms of anxiety, affective and somatic disorder symptoms and aggressive behavior. Among mental disorders comorbid with headaches, both migraine and tension-headaches, symptoms of depression and anxiety occurred most often.

We need to ask why patients with symptoms of mental disorders, despite previous medical consultations (at least with the doctor referring for hospitalization), were sent with signs requiring a psychiatric consultation to the neurology department. One can hypothetically assume that a certain percentage of the hospitalized patients could experience mental deterioration due to stress associated with the situation of hospitalization, which could directly contribute to the disclosure of the psychopathological symptoms. However, the reason for remaining without the proper medical care or prolonging the time before the first consultation with a psychiatrist is very often a desire to avoid the stigmatization with a mental illness. The problem of stigmatization of patients with mental disorders is a key issue, whereas understanding the psychological aspect of the resistance to consult a psychiatrist and the fear of mental illness enables one to better understand the families of children and adolescents with signs of psychiatric problems and to accept their attitudes [27]. Nevertheless, this does not change the fact that the attitude of "dodging" or resisting treatment increases the risk of unwanted complications and exposes the patient to persistent psychological distress.

It is possible that in some patients, the pretext for referring them to the neurology department was to exclude organic etiologies of the already observed psychiatric disorders. Nevertheless, according to the procedures binding in the Department of Developmental Neurology, diagnostic neurological patients are admitted in the so-called elective order, and it seems that waiting for the date of admission could be a dangerous extension of the period between the emergence of alarming symptoms and arriving at the diagnosis, especially in the case of patients with suicidal ideation or positive symptoms. Remaining without the proper psychiatric care is a common problem in different healthcare systems around the world - hence the development of, for instance, telepsychiatry [28].

The results presented in this article point to a gap in the management of patients with symptoms of mental disorders in the general healthcare of children and adolescents. In cases where a mental illness begins with "acute" symptoms, the sudden collapse of functioning (e.g. sudden, acute psychosis) causes much more alarm than changes that increase progressively. Still, as shown by the available reports, the period that patients with a first psychotic episode remain without the proper medical care can last months [29]. In a far worse situation are individuals in the case of whom the course of the disease takes the form of "subtle" changes in behavior. Moreover, when other disorders, such as neurological diseases, have been diagnosed earlier, it is much easier, due to the reasons described above, to attribute the changes in behavior to causes other than mental disorders. An invaluable role in aiding the identification of alarming psychopathological symptoms in patients of a pediatric neurology department is played by a team of child psychologists (Kaczmarek, in press). It is, to a large extent, thanks to their knowledge of the rules of human mental development and the ability to create a proper relationship with a hospitalized child or adolescent that it becomes possible to identify the need to consult a neurologically ill patient with a psychiatrist. What is more, the results of psychological testing, especially intelligence and neuropsychological testing, can reveal significant deficits in the functioning of cognitive processes, characteristic not only of neurological diseases but also mental disorders [3].

In conclusion, taking into consideration the fact that the majority of mental illnesses have their origin in the first two decades of life, research on the development of mental health problems in healthy populations and in clinical groups, including patients with neurological diseases, is a burning issue. A limitation of the conducted research is the fact that the obtained data come exclusively from one pediatric neurology department. The data do not, therefore, enable us to make generalizations about the frequency of mental disorders in patients with neurological diseases and vice versa. However, the conducted studies call attention to the necessity for careful observation and taking into consideration the possibility of co-occurrence of mental disorders in patients from developmental neurology departments. Each patient 
requires an individualized approach to the history of his/her illness and care provided by a multidisciplinary team of specialists, including a psychologist. An in-depth interview and building a relationship based on trust between the child/adolescent and the specialist are still considered to be the most important diagnostic tools. An invaluable role in the department of developmental neurology is played by a team of psychologists who, using their experience, professional skills and diagnostic tools, contribute significantly to the diagnosis of mental disorders in such a narrowly specialized department.

\section{Conflict of interest}

The authors declare no conflict of interest.

\section{References}

1. Testa A, Giannuzzi R, Daini S, Bernardini L, Petrongolo L, Gentiloni Silveri N. Psychiatric emergencies (part III): psychiatric symptoms resulting from organic diseases. Eur Rev Med Pharmacol Sci 2013; 17 Suppl. 1: 86-99.

2. Testa A, Giannuzzi R, Sollazzo F, Petrongolo L, Bernardini L, Daini S. Psychiatric emergencies (part I): psychiatric disorders causing organic symptoms. Eur Rev Med Pharmacol Sci 2013; 17 Suppl. 1: 55-64.

3. Butler C, Zeman AZ. Neurological syndromes which can be mistaken for psychiatric conditions. J Neurol Neurosurg Psychiatry 2005; 76 Suppl. 1: i31-8.

4. Nunes ML, Bruni O. Insomnia in childhood and adolescence: clinical aspects, diagnosis, and therapeutic approach. J Pediatr (Rio J) 2015; 91 (6 Suppl. 1): S26-35.

5. Krysiak-Rogala K, Jernajczyk W. Sleep disturbances in children and adolescents with psychiatric disorders affective and anxiety disorders [Polish]. Psychiatr Pol 2013; 47: 303-12.

6. Testa A, Giannuzzi R, Sollazzo F, Petrongolo L, Bernardini L, Dain S. Psychiatric emergencies (part II): psychiatric disorders coexisting with organic diseases. Eur Rev Med Pharmacol Sci 2013; 17 Suppl. 1: 65-85.

7. Verrotti A, Carrozzino D, Milioni M, Minna M, Fulcheri M. Epilepsy and its main psychiatric comorbidities in adults and children. J Neurol Sci 2014; 343: 23-9.

8. Matzova Z, Skodacek I, Suba J, Bohmer F. Comparison of history of adolescents with substance-induced psychosis, early onset schizophrenia and substance use disorders. Bratisl Lek Listy 2014; 115: 771-5.

9. Beecham J. Annual research review: child and adolescent mental health interventions: a review of progress in economic studies across different disorders. J Child Psychol Psychiatry 2014; 55: 714-32.

10. Cuffe SP, Visser SN, Holbrook JR, et al. ADHD and psychiatric comorbidity: functional outcomes in a schoolbased sample of children. J Atten Disord 2015 Epub ahead of print.

11. Verlinden E, Opmeer BC, Van Meijel EP, et al. Enhanced screening for posttraumatic stress disorder and comorbid diagnoses in children and adolescents. Eur J Psychotraumatol 2015; 6: 26661.

12. Masi G, Millepiedi S, Perugi G, et al. A naturalistic exploratory study of the impact of demographic, phenotypic and comorbid features in pediatric obsessive-compulsive disorder. Psychopathology 2010; 43: 69-78.
13. Bellini B, Arruda M, Cescut A, et al. Headache and comorbidity in children and adolescents. J Headache Pain 2013; 14: 79.

14. Dyb G, Stensland S, Zwart JA. Psychiatric comorbidity in childhood and adolescence headache. Curr Pain Headache Rep 2015; 19: 5.

15. Buse DC, Silberstein SD, Manack AN, Papapetropoulos S, Lipton RB. Psychiatric comorbidities of episodic and chronic migraine. J Neurol 2013; 260: 1960-9.

16. Pringsheim T, Hammer T. Social behavior and comorbidity in children with tics. Pediatr Neurol 2013; 49: 406-10.

17. Hirschtritt ME, Lee PC, Pauls DL, et al. Lifetime prevalence, age of risk, and genetic relationships of comorbid psychiatric disorders in Tourette syndrome. JAMA Psychiatry 2015; 72: 325-33.

18. Goretti B, Ghezzi A, Portaccio E, et al. Psychosocial issue in children and adolescents with multiple sclerosis. Neurol Sci 2010; 31: 467-70.

19. Plioplys S, Dunn DW, Caplan R. 10-year research update review: psychiatric problems in children with epilepsy. J Am Acad Child Adolesc Psychiatry 2007; 46: 1389-402.

20. Luby JL, Navsaria N. Pediatric bipolar disorder: evidence for prodromal states and early markers. J Child Psychol Psychiatry 2010; 51: 459-71.

21. Luby JL. Preschool depression: the importance of identification of depression early in development. Curr Dir Psychol Sci 2010; 19: 91-5.

22. Richter M, Vereecken CA, Boyce W, Maes L, Gabhainn $\mathrm{SN}$, Currie CE. Parental occupation, family affluence and adolescent health behaviour in 28 countries. Int J Public Health 2009; 54: 203-12.

23. Mazur J, Malkowska-Szkutnik A. Chronic diseases and perception of school demands among school children aged 11-15 years in Poland [Poland]. Med Wieku Rozwoj 2010; 14: 160-8.

24. Shanahan L, Zucker N, Copeland WE, Bondy CL, Egger HL, Costello EJ. Childhood somatic complaints predict generalized anxiety and depressive disorders during young adulthood in a community sample. Psychol Med 2015; 45: 1721-30.

25. Davies S, Heyman I, Goodman R. A population survey of mental health problems in children with epilepsy. Dev Med Child Neurol 2003; 45: 292-5.

26. Jones JE, Siddarth P, Gurbani S, Shields WD, Caplan R. Screening for suicidal ideation in children with epilepsy. Epilepsy Behav 2013; 29: 521-6.

27. Mukolo A, Heflinger CA, Wallston KA. The stigma of childhood mental disorders: a conceptual framework. J Am Acad Child Adolesc Psychiatry 2010; 49: 92-103; quiz 98.

28. Ellington E, McGuinness TM. Telepsychiatry for children and adolescents. J Psychosoc Nurs Ment Health Serv 2011; 49: 19-22.

29. Birchwood M, Connor C, Lester H, et al. Reducing duration of untreated psychosis: care pathways to early intervention in psychosis services. Br J Psychiatry 2013; 203: 58-64. 